\title{
Evaluation of the levofloxacin release characters from a rabbit foldable capsular vitreous body
}

This article was published in the following Dove Press journal:

International Journal of Nanomedicine

29 December 201I

Number of times this article has been viewed

\section{Zhaoxin Jiang' \\ Ting Wang' \\ Biyan Pan ${ }^{2}$ \\ Zhiyong $\mathrm{Xie}^{2}$ \\ Peijuan Wang' \\ Yaqin Liu' \\ Qianying Gao'}

'State Key Laboratory of Ophthalmology, Zhongshan Ophthalmic Center, Sun Yat-sen University, Guangzhou, People's Republic of China; '2Laboratory of Pharmaceutical Analysis and Quality Assessment, School of Pharmaceutical Sciences, Sun Yat-sen University, Guangzhou,

People's Republic of China
Correspondence: Qianying Gao State Key Laboratory of Ophthalmology, Zhongshan Ophthalmic Center, Sun Yat-sen University, Guangzhou 510060 , People's Republic of China Tel +862087330490

Fax +86 2087331350

Email gaoqy@mail.sysu.edu.cn
Abstract: The authors have manufactured a novel rabbit foldable capsular vitreous body (FCVB). The aim of this study was to determine whether this rabbit FCVB can release levofloxacin in vitro and in vivo, and to evaluate the release characteristics. In vitro, the rabbit FCVB with levofloxacin $500 \mu \mathrm{g} / \mathrm{mL}$ was immersed in cups of modified Franz diffusion cells. Following this, $200 \mu \mathrm{L}$ of liquid was aspirated at intervals from 10 minutes to 24 hours. In vivo, the FCVB with levofloxacin was implanted into the right eyes of five rabbits. After implantation, the aqueous humor was aspirated on days $1,7,14,28$, and 56. The levofloxacin concentrations in the cups and aqueous humor samples were detected by high-performance liquid chromatography-tandem mass spectrometry. The FCVB was observed under a scanning electron microscope. The results showed that the released levofloxacin was stabilized at $20 \mathrm{ng} / \mathrm{mL}$ at time points from 10 minutes to 24 hours in vitro. In vivo, levofloxacin concentrations in the aqueous humor were 132, 50, 39, 11, and $15 \mathrm{ng} / \mathrm{mL}$ on days $1,7,14,28$, and 56, respectively. In the FCVB capsules, $300 \mathrm{~nm}$ apertures were observed. These results suggest the rabbit FCVB released levofloxacin stably in vitro and sustainably in vivo. This study provides a novel combined approach, with the FCVB as a vitreous substitute and drug delivery system for the treatment of bacterial endophthalmitis.

Keywords: drug delivery system, high-performance liquid chromatography-tandem mass spectrometry, vitreous substitute, bacterial endophthalmitis

\section{Introduction}

Bacterial endophthalmitis is a rare but catastrophic complication of intraocular surgery and penetrating injuries. ${ }^{1}$ The overall incidence of endophthalmitis following cataract surgery in the United States is about $0.1 \% .^{2}$ Endophthalmitis occurs at a much higher rate with penetrating ocular injuries than with surgery: from $2 \%$ to $16 \%$ of eyes develop microbial endophthalmitis. ${ }^{3}$ Retinal detachment is one of the most serious complications of endophthalmitis and it occurs with an incidence rate of from $4 \%$ to $21 \%{ }^{1}$ The visual outcome is poor, with most cases leading to blindness in the affected eye. ${ }^{4}$ Many patients have extraocular foci of infection, with an associated mortality rate of $5 \%{ }^{4}$

As for the drugs used for therapy, an intravitreal first-line drug therapy is recommended: vancomycin $(1.0 \mathrm{mg} / 0.1 \mathrm{~mL})$ to cover Gram-positive microorganisms and ceftazidime $(2.25 \mathrm{mg} / 0.1 \mathrm{~mL})$ to cover Gram-negative microorganisms. ${ }^{5}$ However, ceftazidime is physically incompatible with vancomycin, and it is therefore necessary to inject the two antibiotics from separate syringes to avoid precipitation of the drugs. ${ }^{6,7}$ There has been a recent drive in ophthalmology to explore the clinical potential of fluoroquinolones. ${ }^{8}$ Levofloxacin is a third-generation fluoroquinolone and it is the 
antibacterially active L-isomer of the racemate ofloxacin. Levofloxacin has activity against both Gram-positive and Gram-negative bacteria. ${ }^{9}$ Various studies have been carried out to determine the safety and efficacy of levofloxacin as a treatment for conjunctivitis and keratitis ${ }^{10,11}$ and of intravitreal levofloxacin in Staphylococcus epidermidis endophthalmitis. ${ }^{8,12}$

As the route for administration, systemic antibiotics have been used concurrently for bacterial endophthalmitis. ${ }^{13}$ However, the blood-ocular barrier prevents the entrance and subsequent activity of most systemic antimicrobial and antiinflammatory drugs. ${ }^{3}$ The recommended management of bacterial endophthalmitis includes direct injections of antibiotics into the vitreous. ${ }^{2}$ However, this method of treatment is fraught with risks. Direct intravitreal injections increase the risk of retinal detachments, cataracts, vitreous hemorrhage, and endophthalmitis. ${ }^{14}$ Photoreceptors and other cells of the retina are exquisitely sensitive to the antimicrobial agents and the biochemical pathways necessary for vision may potentially be disrupted. ${ }^{3}$ An intravitreal drug delivery system (DDS) is a feasible solution to this unique dilemma. ${ }^{15,16}$

In previous studies, the authors have proposed a new strategy to replace the natural vitreous body using a novel foldable capsular vitreous body (FCVB). ${ }^{17-21}$ The FCVB consisted of a thin, vitreous-shaped capsule with a tube-valve system created using a computer and industrial technology. After the foldable installation into the eye, a balanced salt solution was injected to inflate the capsule and support the retina and control the intraocular pressure through the tubevalve system. ${ }^{17}$ Interestingly, the FCVB changes the refraction very little compared with silicone oil and heavy silicone oil, based on the Gullstrand-Emsley and Liou-Brennan schematic eyes. ${ }^{18}$ Reports from the Chinese State Food and Drug Administration (No. G20080656) and additional tests according to guidelines of the International Organization for Standardization show that the FCVB has good mechanical, optical, and biocompatible properties. ${ }^{19}$ An exploratory clinical trial conducted at the Zhongshan Ophthalmic Center, Sun Yat-sen University, China, showed that the FCVB was a flexible, effective, and safe vitreous substitute over a 3-month implantation period in human eyes. ${ }^{20}$ Moreover, the FCVB can sustainably and mechanically release dexamethasone sodium phosphate (DexP) and may be used as an intravitreal DDS for DexP. ${ }^{21}$ The purpose of this article is to evaluate whether the rabbit FCVB could release levofloxacin in vitro and in vivo and whether it could provide a combined therapy strategy as a vitreous substitute and DDS for the treatment of bacterial endophthalmitis.

\section{Material and methods Basic materials and fabrication of the rabbit FCVB}

The rabbit FCVB was fabricated with tailor-made modified liquid silicone rubber. The basic material, Dow Corning Class VI elastomer, was purchased from Dow Corning Corporation (Midland, MI). The liquid silicone rubber was gelatinous at room temperature $\left(20^{\circ} \mathrm{C}\right)$. Vulcanized at $160^{\circ} \mathrm{C}$ with a heating duration of 200 seconds, the material became semisolid elastic rubber.

The rabbit FCVB was fabricated using injection-molding technology in a specially designed mirror steel mold. The core of the mold precisely mimics the shape of the vitreous body of the rabbit. The gaps in the mold control the thickness of the capsular film to as thin as $30 \mu \mathrm{m} .{ }^{19}$

\section{Levofloxacin released in vitro}

Levofloxacin powder (Livzon Pharmaceutical Group Inc, Zhuhai, Guangdong, China) was dissolved aseptically in distilled water $\left(\mathrm{H}_{2} \mathrm{O}\right)$ to a final concentration of $500 \mu \mathrm{g} / \mathrm{mL}$. In vitro, $1.0 \mathrm{~mL}$ of this solution was injected into the capsules of the rabbit FCVB and these FCVBs were then immersed in cups of modified Franz diffusion cells. Following this, $200 \mu \mathrm{L}$ of the liquid in each cup was aspirated for measurement at 10 , 20, and 40 minutes and 1, 6, 9, 12, and 24 hours (Figure 1). The levofloxacin content in the liquid was then detected by sensitive high-performance liquid chromatography-tandem mass spectrometry (HPLC-MS/MS) (Thermo Finnigan LLC, San Jose, CA).

\section{Levofloxacin released in vivo}

For the in vivo study, the capsule was folded and implanted into the vitreous cavity after pars plana vitrectomy (PPV), then levofloxacin $1.0 \mathrm{~mL}(500 \mu \mathrm{g} / \mathrm{mL})$ was injected into the capsule (Figure 2). In the control group, levofloxacin was injected into the vitreous cavity of three rabbits after PPV. The aqueous humor was aspirated on days 1, 7, 14, 28, and 56 after implantation. The levofloxacin concentrations in the aqueous humor were detected by the HPLC-MS/MS method. All experimental procedures adhered to the Association for Research in Vision and Ophthalmology Resolution on the Use of Animals in Ophthalmic and Vision Research. The care of animals involved in experiments was in accordance with the guidelines of the Zhongshan Ophthalmic Center.

Before all surgical procedures, five New Zealand albino rabbits weighing $2.0-2.5 \mathrm{~kg}$ were anesthetized by an intramuscular injection of ketamine hydrochloride $(30 \mathrm{mg} / \mathrm{kg})$ and 

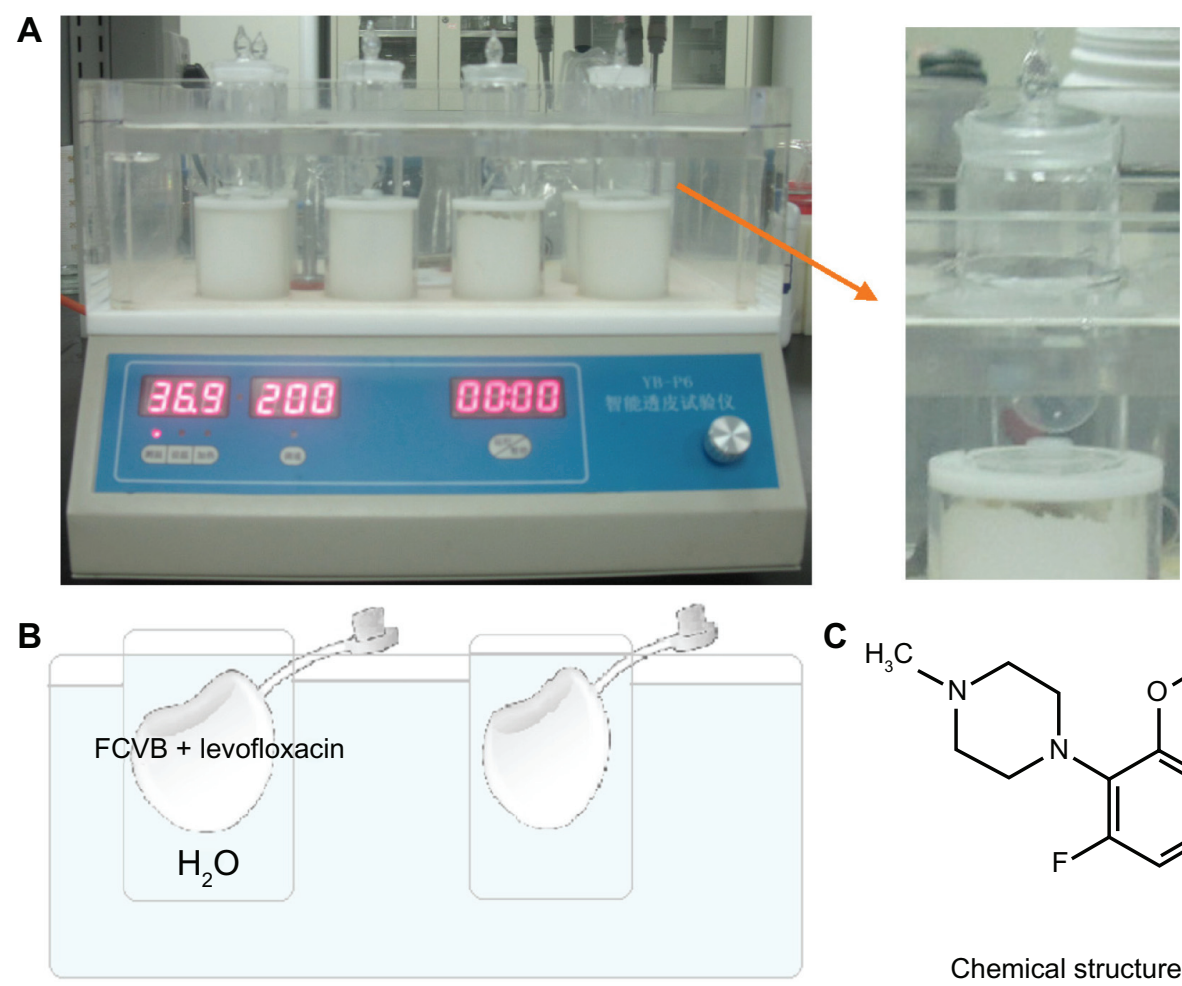

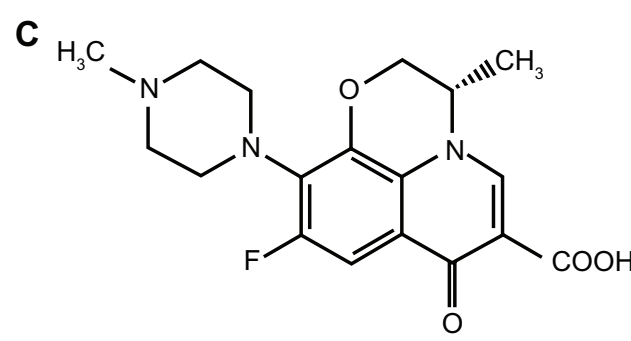

Chemical structure of levofloxacin

Figure I (A) Rabbit foldable capsular vitreous body (FCVB) filled with levofloxacin was immersed in cups of modified Franz diffusion cells, (B) a simple diagram of the releasing cell, and $(\mathbf{C})$ the chemical structure of levofloxacin.

chlorpromazine hydrochloride ( $15 \mathrm{mg} / \mathrm{kg})$. Pupils were dilated with $0.5 \%$ tropicamide (Shenyang Xingqi Pharmaceutical Co, Ltd, Shenyang, China). PPV was performed, and the FCVB was implanted in the right eyes of the rabbits. A standard three-port PPV was performed on the right eye of each rabbit using a vitrectomy machine (Geuder, Heidelberg, Germany).
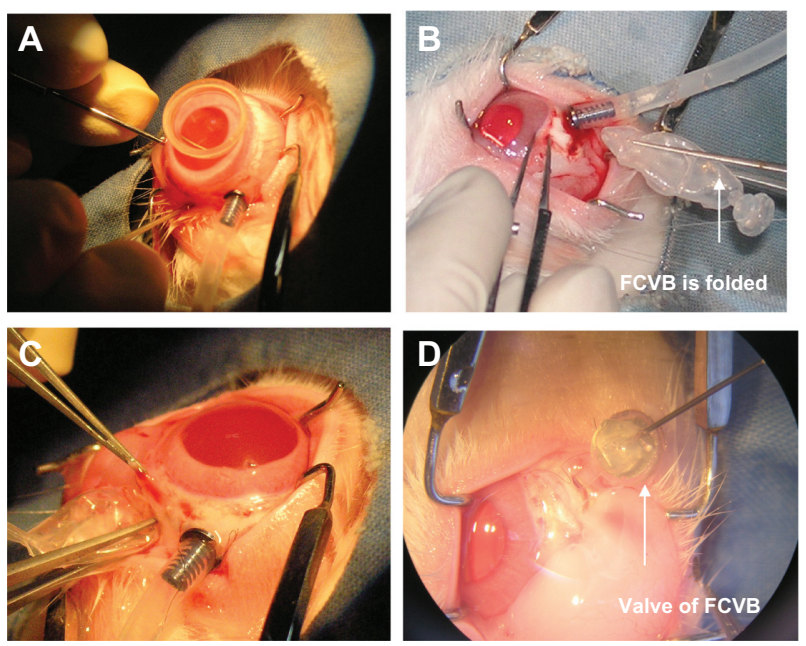

Figure 2 Rabbit foldable capsular vitreous body (FCVB) with levofloxacin was implanted in vivo. (A) Pars plana vitrectomy was performed on the right eye, (B) the capsule of FCVB was folded, (C) FCVB was implanted into the vitreous cavity, and (D) levofloxacin solution was injected into the capsule through the valve.
After the vitrectomy, the capsule was folded and implanted into the vitreous cavity after a fluid-air exchange. Approximately $1.0 \mathrm{~mL}$ of levofloxacin $(500 \mu \mathrm{g} / \mathrm{mL})$ was injected into the capsule through a silicone tube-valve system, and thus the capsule was inflated to support the retina. The tube was subsequently fixed under the conjunctiva. The operation concluded with a subconjunctival injection of gentamicin and dexamethasone and with the application of compound tobramycin and atropine (1\%) ointment. The animals were anesthetized on days 1, 7, 14, 28, and 56 after implantation, and $0.1-0.2 \mathrm{~mL}$ of aqueous humor was aspirated from both eyes of each rabbit. The aqueous humor samples were examined by the sensitive HPLC-MS/MS method.

\section{Levofloxacin sample assay}

The HPLC-MS/MS system consists of a Surveyor MS Pump and Autosampler (Thermo Finnigan) and a TSQ Quantum triple quadrupole mass spectrometer (Thermo Finnigan) equipped with an ESI source (Thermo Finnigan). A reversed-phase column XTerra C18 $(3 \mathrm{~mm} \times 150 \mathrm{~mm}$, $3.5 \mu \mathrm{m}$; Waters Corporation, Milford, MA) was used for all chromatographic separation at room temperature $\left(20^{\circ} \mathrm{C}\right)$. For the levofloxacin sample in vitro, the mobile phase ( $1 \%$ formic acid in $\mathrm{H}_{2} \mathrm{O}$ and acetonitrile, 40:60, v/v) was 
pumped at a flow rate of $0.3 \mathrm{~mL} / \mathrm{min}$. For the levofloxacin sample in vivo, the mobile phase ( $1 \%$ formic acid in $\mathrm{H}_{2} \mathrm{O}$ and formic acid, 75:25, v/v) was pumped at a flow rate of $0.2 \mathrm{~mL} / \mathrm{min}$. The mass spectrometer was operated in the positive electrospray ionization mode. Quantification was performed using selected reaction monitoring (SRM) in the positive mode. The ion transition of the mass-to-charge ratio $(\mathrm{m} / \mathrm{z}) 361.7 \rightarrow 318.0$ for levofloxacin was monitored, with a collision-induced energy of $18 \mathrm{eV}$.

The reference formulation of levofloxacin (purity of 99.99\%, lot number 30537-200301) was obtained from the National Institute for the Control of Pharmaceutical and Biological Products, China. Acetonitrile and methanol of HPLC grade were purchased from SK Chemicals, Korea. Formic acid of HPLC grade was purchased from Merck (State Food and Drug Administration, Guangzhou, China).

The stock solutions were prepared in methanol at a concentration of $20 \mu \mathrm{g} / \mathrm{mL}$ in $100 \mathrm{~mL}$ glass vials and were serially diluted with methanol to prepare standard working solutions at the desired concentrations: 5, 10, 50, 100, 500, 800 , and $1000 \mathrm{ng} / \mathrm{mL}$. From there, $30 \mu \mathrm{L}$ samples were transferred into $2.0 \mathrm{~mL}$ Eppendorf tubes. After adding $30 \mu \mathrm{L}$ of Cip solution (IS), $30 \mu \mathrm{L}$ of methanol, and $300 \mu \mathrm{L}$ of mobile phase, the mixture was vortexed for 1 minute and centrifuged at 12,000 rpm for 5 minutes. Approximately $0.1 \mathrm{~mL}$ of the supernatant was transferred into autosampler vials, and then $10 \mu \mathrm{L}$ was injected into the HPLC column. Data acquisition was performed with Xcalibur software (v 1.3; Thermo Finnigan). Peak integration and calibration were performed using LCquan software (v 1.3; Thermo Finnigan).

\section{Scanning electron microscopy of the FCVB}

The capsules of the rabbit FCVB were observed under a scanning electron microscope (ESEM XL-30; Philips, the Netherlands) before and after these release studies. The capsules were cut to the appropriate size, and the visible surface of each sample was cleaned and coated with aurum by sputter coating (BAL-TEC SCD 005, Bal-Tec Co, Balzers, Liechtenstein) at $30 \mathrm{~mA}$ for 90 seconds. Samples were fixed on a specimen stub and images of the surface of each specimen were captured on the scanning electron microscope.

\section{Results}

The standard weight of the rabbit FCVB was $0.21 \pm 0.005 \mathrm{~g}$, and the standard volume was $1.0 \pm 0.5 \mathrm{~mL}$. The FCVB was transparent with light transmittance levels as high as $92 \%$, and the thickness of the capsule was $60 \mu \mathrm{m}$ (Figure 3 ).

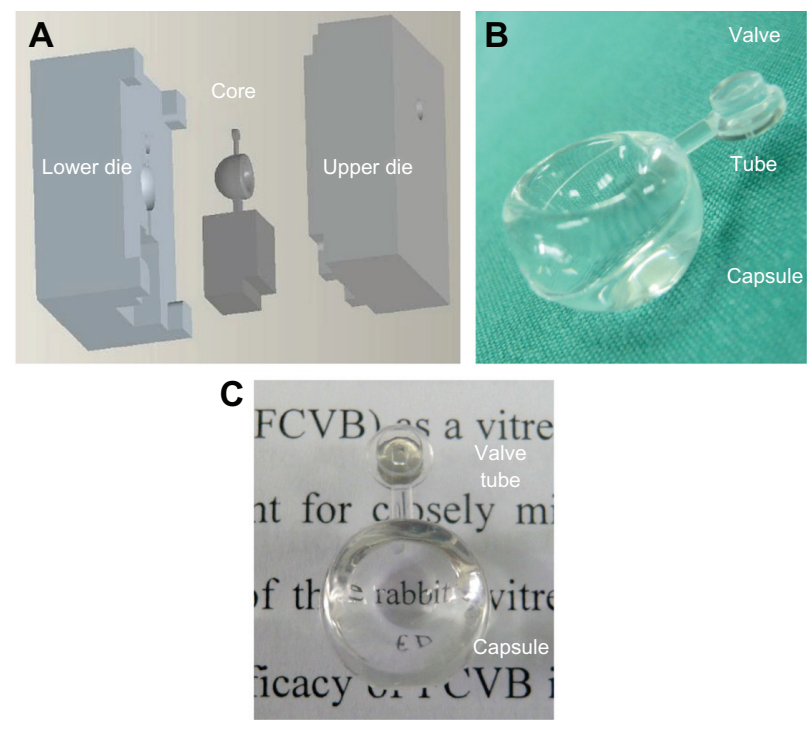

Figure 3 Steel mold and production of rabbit foldable capsular vitreous body (FCVB). (A) The mold for rabbit FCVB consisted of a core and lower and upper dies, (B) fabricated rabbit FCVB, and (C) the rabbit FCVB is highly transparent.

The representative mass spectra of levofloxacin, HPLCMS/MS chromatograms, accuracy, and precision of the quality control (QC) samples are shown in Figures 4 and 5 and in Table 1. Levels of levofloxacin released in vitro and in vivo are shown in Figures 6 and 7.

The HPLC-MS/MS parameters were optimized to produce the maximum response for levofloxacin in the positive ion mode. After electrospray ionization, positive ion fragments of $\mathrm{m} / \mathrm{z} 361.7$ were detected in the SRM mode with a triple quadrupole mass spectrometer, and the fragment ions of $\mathrm{m} / \mathrm{z} 318.0$ were chosen as the production for monitoring levofloxacin. Fragment ions of $\mathrm{m} / \mathrm{z} 332.2 \rightarrow 314.0$ were chosen for internal standard ciprofloxacin (Figure 4).

In representative HPLC-MS/MS chromatograms, $\mathrm{H}_{2} \mathrm{O}$ as a background solvent does not interfere with the channel of levofloxacin. Retention time of ciprofloxacin was 2.25 minutes. This internal standard ciprofloxacin achieves the baseline separation with the impurities in $\mathrm{H}_{2} \mathrm{O}$ and does not interfere with the channel of levofloxacin. Retention time of levofloxacin was 2.2 minutes, thus achieving the baseline separation with the impurities in $\mathrm{H}_{2} \mathrm{O}$ (Figure 5).

The accuracy (relative error [RE], \%) and precision (relative standard deviation [RSD],\%) results for the QC samples are summarized in Table 1 . The results of $\mathrm{RE} \leq \pm 15 \%$ and RSD $\leq \pm 15 \%$ proved the acceptable level of accuracy and precision of the proposed method.

Rabbit FCVB can release levofloxacin in vitro. The results showed that the released levofloxacin was $20 \mathrm{ng} / \mathrm{mL}$ at the 10 -minute time point and then stabilized as $20 \mathrm{ng} / \mathrm{mL}$ over 
A lev-MS1-MS2\#190 RT: 2.85 AV: 1 NL: 1.68E6

A T: tc sid =-10.00 Full ms2 361.60@25.00 [50.00-400.00]

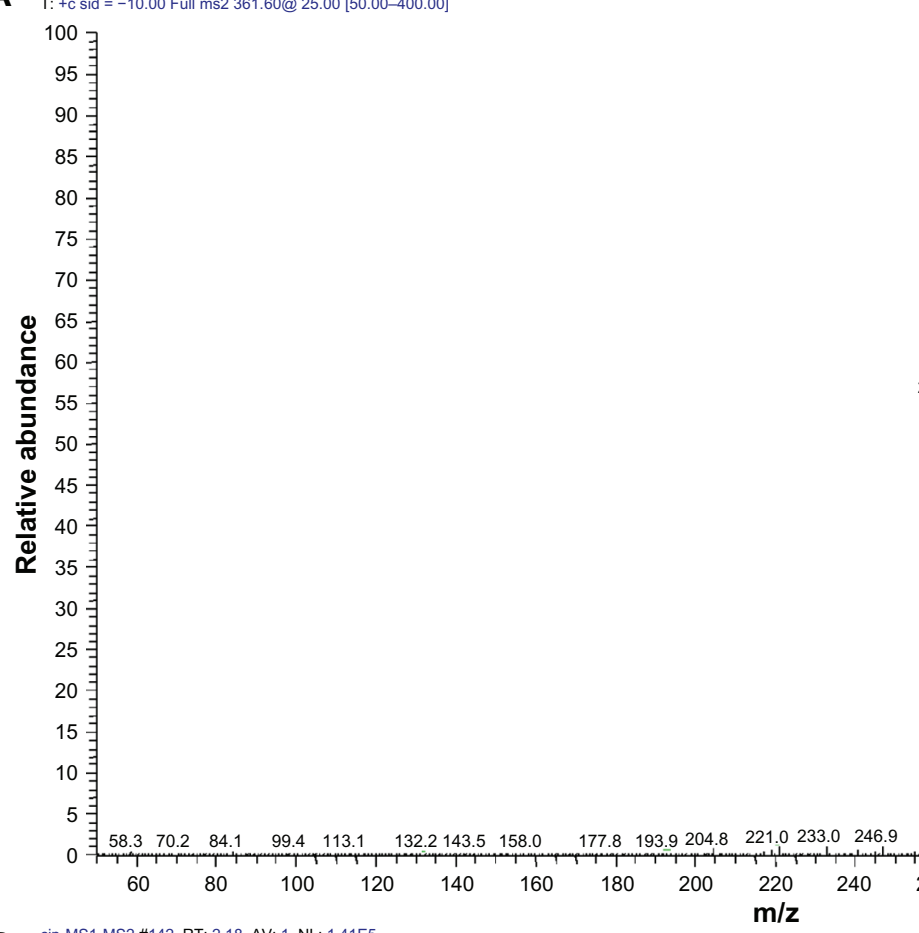

318.0

B T: tc sid $=-10.00$ Full ms2 $332.00 @ 22.00[50.00-400.00]$

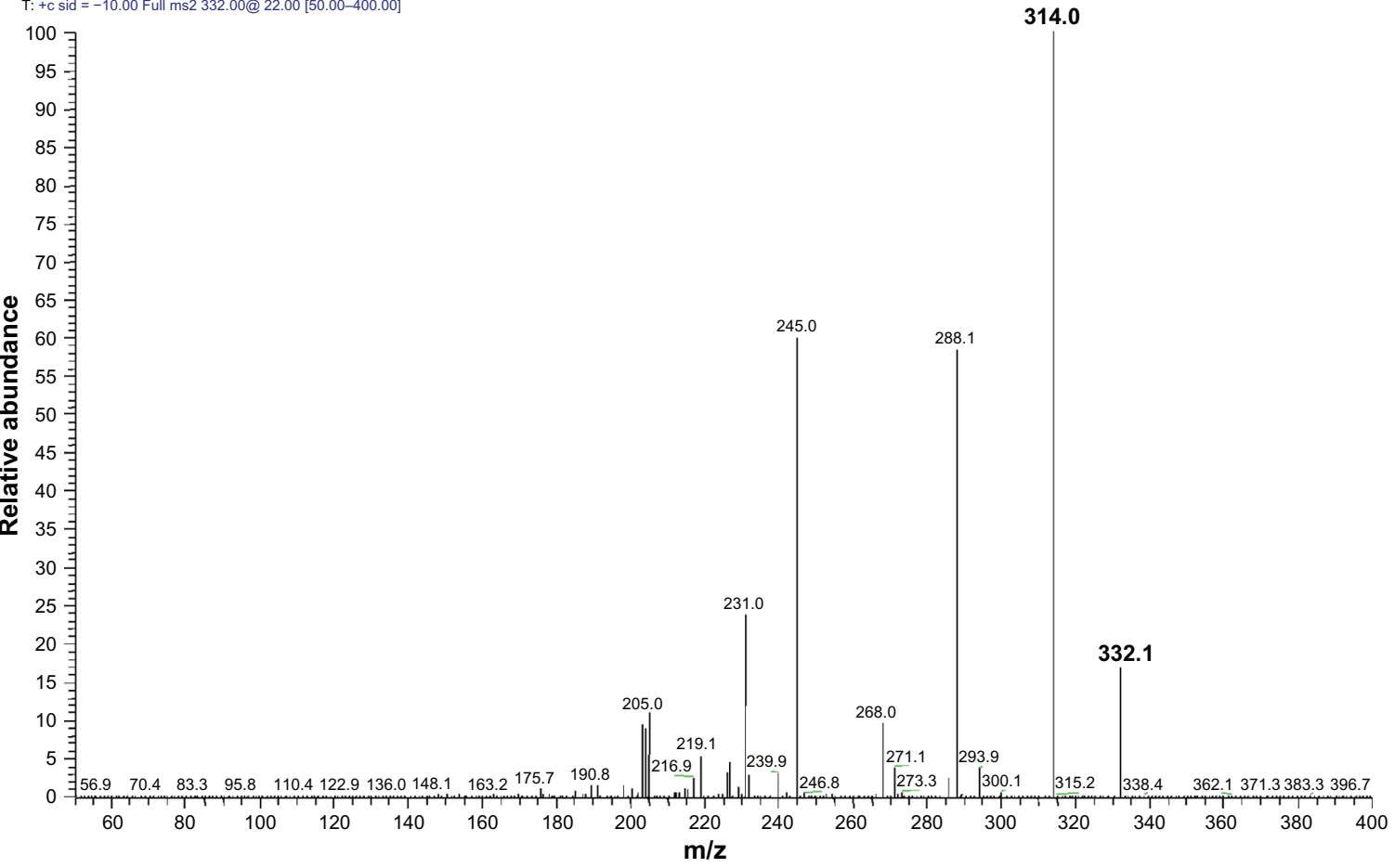

Figure 4 The production mass spectra of abundant protonated molecular ions $([\mathrm{M}+\mathrm{H}]+)$ for levofloxacin and ciprofloxacin. (A) Fragment ions of mass-to-charge ratio $(\mathrm{m} / \mathrm{z})$ $362.0 \rightarrow 318.1$ were chosen as the production for monitoring levofloxacin and (B) fragment ions of $\mathrm{m} / \mathrm{z} 332.2 \rightarrow 314.0$ were chosen for ciprofloxacin.

the following observation period (Figure 6). The relationships between concentration $(\mathrm{Q})$ and time $\left(\mathrm{t}^{1 / 2}\right)$ were described with Higuchi equation: $\mathrm{Q}=-0.113 \mathrm{t}^{1 / 2}+20.01(r=0.625)$. The concentrations at different time points showed no significant difference $(\mathrm{F}=4.366 ; P>0.05)$ (Table 2$)$.
Rabbit FCVB can release levofloxacin in vivo. On the first day after rabbit FCVB implantation, the levofloxacin concentration in the aqueous humor was $132 \mathrm{ng} / \mathrm{mL}$. On days 7,14 , and 28 , the levofloxacin was sustained as 50,39 and $11 \mathrm{ng} / \mathrm{mL}$, respectively. Levofloxacin was still detectable 

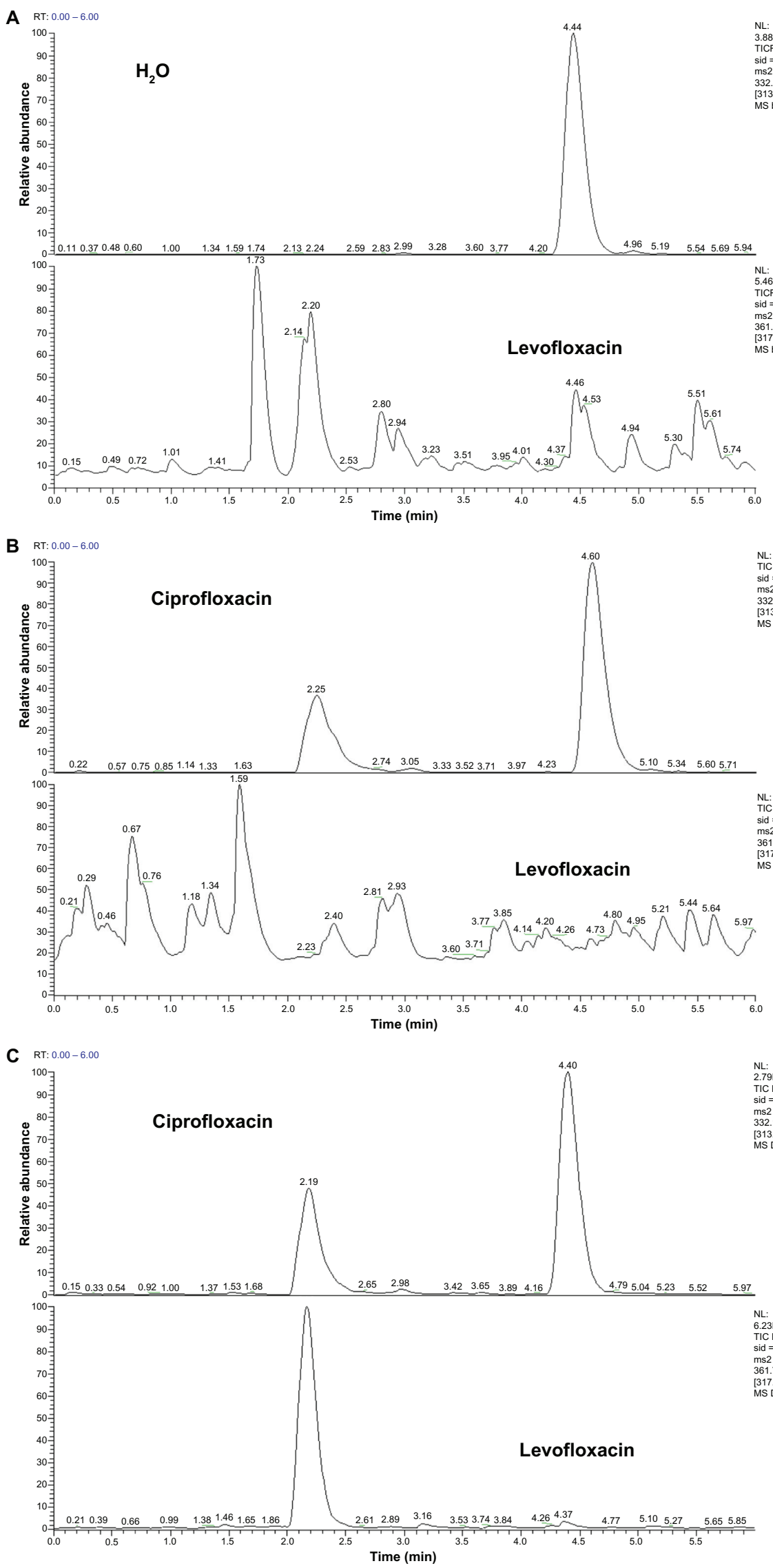

Figure 5 Representative high-performance liquid chromatography-tandem mass spectrometry chromatograms of $(\mathbf{A})$ blank water $\left(\mathrm{H}_{2} \mathrm{O}\right),(\mathbf{B})$ blank $\mathrm{H}_{2} \mathrm{O}$ with internal standard ciprofloxacin, and (C) blank $\mathrm{H}_{2} \mathrm{O}$ with a sample of levofloxacin. 
Table I Summary of accuracy and precision of quality control samples in high-performance liquid chromatography-tandem mass spectrometry detection

\begin{tabular}{lllll}
\hline Added $(\mathrm{ng} / \mathrm{mL})$ & Found $(\mathrm{ng} / \mathrm{mL})$ & SD (\%) & RSD (\%) & RE (\%) \\
\hline 10.00 & 11.43 & 0.72 & 6.73 & 7.00 \\
& 10.68 & & & \\
& 9.99 & & & \\
100.00 & 107.59 & 7.76 & 7.41 & 4.66 \\
& 95.87 & & & \\
& 110.53 & & & \\
800.00 & 854.21 & 57.66 & 7.31 & -1.93 \\
& 767.29 & & & \\
Linear equation & 745.13 & & & \\
Correlation & $\mathrm{Y}=-0.0067+0.0085 \mathrm{X}$ & & \\
coefficient $\left(r^{2}\right)$ & 0.9936 & & & \\
\hline
\end{tabular}

Abbreviations: RE, relative error; RSD, relative standard deviation; SD, standard deviation.

at $15 \mathrm{ng} / \mathrm{mL}$ on day 56 . In the control group, the levofloxacin was 183 and $9 \mathrm{ng} / \mathrm{mL}$ on days 1 and 7 after intravitreal injection. The levofloxacin could not be detected on day 14 (Figure 7).

In the scanning electron microscope images, numerous $300 \mathrm{~nm}-\mathrm{mm}$ apertures were observed in the capsule of the rabbit FCVB at the beginning and end of the observations, as shown in Figure 8.

\section{Discussion}

Endophthalmitis is defined as any inflammation of the internal ocular spaces, and it potentially results in poor visual prognoses for the majority of patients. ${ }^{4}$ An intravitreal DDS is the consensus ideal method for drug administration into the vitreous body. ${ }^{15}$ This study demonstrates that the rabbit
FCVB can sustainably and mechanically release levofloxacin in vitro and in vivo and it may provide a new combined research and therapy strategy as a vitreous substitute and DDS for the treatment of bacterial endophthalmitis.

The use of levofloxacin for endophthalmitis has been previously described by Jackson et al, ${ }^{4}$ Herbert et al, ${ }^{22}$ Yildirim et al, ${ }^{12}$ Ferrer et al, ${ }^{8}$ and Gurler et al. ${ }^{23}$ Jackson et al, ${ }^{4}$ after reviewing 267 reported cases, demonstrated that the most common Gram-positive organisms are Staphylococcus aureus and Streptococcus pneumoniae. Herbert et $\mathrm{al}^{22}$ reported that levofloxacin possesses a wide spectrum in vitro against both Gram-positive and Gram-negative pathogens and suggested that the minimum inhibitory concentration required to inhibit the growth of $90 \%$ of the organisms $\left(\mathrm{MIC}_{90}\right)$ for $S$. aureus is $0.25-0.50 \mu \mathrm{g} / \mathrm{mL}$. Yildirim et $\mathrm{l}^{12}$ demonstrated that intravitreal levofloxacin appeared to be effective in $S$. epidermidis endophthalmitis in rabbits and that the culture results of the treatment groups were sterile. Gurler et $\mathrm{al}^{23}$ established the level of toxicity of intravitreal levofloxacin; the doses of 50, 100,250 , and $500 \mu \mathrm{g}$ in $0.1 \mathrm{~mL}$ injected into the mid-vitreous of rabbits were not toxic to the retina.

In this study, rabbit FCVB was demonstrated to have a sustained release of levofloxacin in vitro and in vivo: $300 \mathrm{~nm}-\mathrm{mm}$ apertures in the capsule gave the FCVB the capability of a DDS. The formation of $300 \mathrm{~nm}$ apertures is attributed to the fabrication of FCVB. The liquid silicone rubber was injected into the mold at room temperature $\left(20^{\circ} \mathrm{C}\right)$, and became semisolid elastic rubber after vulcanization. During vulcanizing, air traverses the silicone rubber membrane and leaves nanometer-grade channels. As the molecular mass of levofloxacin is 415.85 daltons, the drug molecules will diffuse freely through

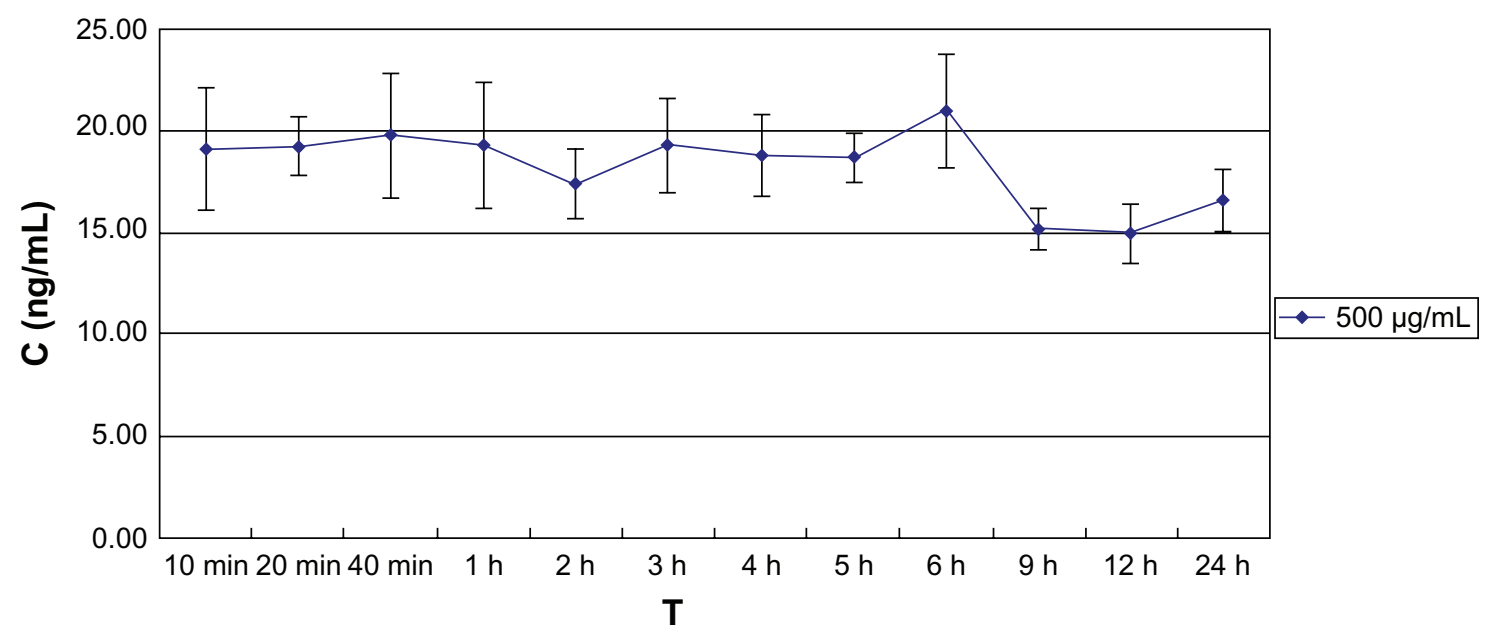

Figure 6 The levofloxacin released from the foldable capsular vitreous body stabilized at $20 \mathrm{ng} / \mathrm{mL}$ in vitro. Abbreviations: $\mathrm{C}$, concentration; $\mathrm{T}$, time. 


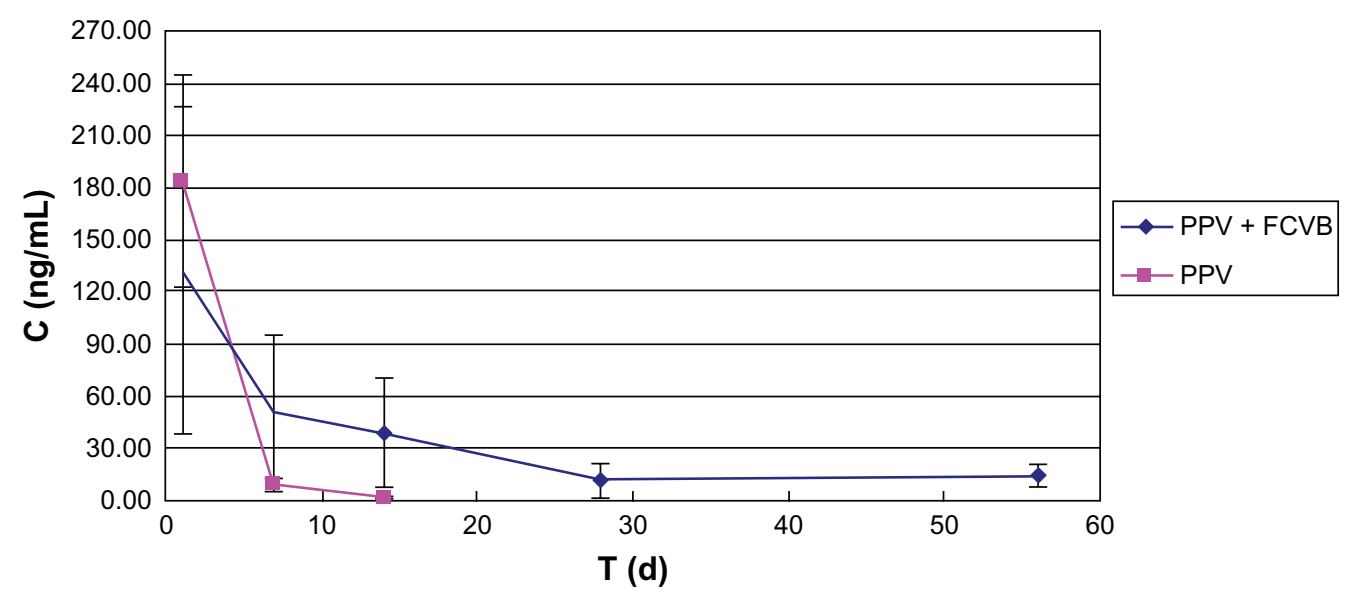

Figure 7 Foldable capsular vitreous body (FCVB) continuously released levofloxacin in vivo. The levofloxacin in the aqueous humor was 132 , 50 , 39, II, and I5 ng/mL on days I, 7, 14, 28, and 56, respectively, after rabbit FCVB implantation. In the control group, the levofloxacin was I83, 9, and $0 \mathrm{ng} / \mathrm{mL}$ on days I, 7, and I4, respectively. Abbreviations: C, concentration; d, days; PPV, pars plana vitrectomy; T, time.

the apertures. The osmotic pressure, as long as the rabbit FCVB with levofloxacin is immersed in $\mathrm{H}_{2} \mathrm{O}$, forces the levofloxacin molecules to move through the apertures to the outer circumstance. In this study, levofloxacin was shown to keep on releasing in vitro. On the other hand, the number of apertures also restricts the total flow rate and limits the rapid loss of the levofloxacin, and then a sustained drug release is achieved. Especially in vivo, as the released levofloxacin is taken away by blood, or metabolized quickly, osmotic pressure maintains the strain. Ohkubo et $\mathrm{al}^{24}$ demonstrated that the levofloxacin concentration was not detectable 1 week after the intravitreal injection in the choroid-retinal pigment epithelium of albino rabbits. In the present study, levofloxacin was still detectable 8 weeks after FCVB implantation.

Intraocular DDS is becoming increasingly important. The need for intraocular DDS has resulted in a variety of controlled-release systems such as implantable devices and injectable particles. ${ }^{15,16}$ Current DDSs such as the dexamethasone intravitreal implant for macular edema and the intravitreal fluocinolone acetonide implant for uveitis ${ }^{25,26}$ have some major disadvantages; for example, they are opaque, they may interfere with vision, or they may result

Table 2 The model fitting results for levofloxacin release from the foldable capsular vitreous body in vitro

\begin{tabular}{lll}
\hline $\begin{array}{l}\text { Kinetic } \\
\text { model }\end{array}$ & Equation & $\mathbf{r}$ \\
\hline Zero & $\mathrm{Q}=-0.002 \mathrm{t}+19.17$ & 0.604 \\
First order & $\ln (100-\mathrm{Q})=-0.00003 \mathrm{t}+4.392$ & 0.602 \\
Higuchi & $\mathrm{Q}=-0.113 \mathrm{t}^{1 / 2}+20.01$ & 0.625 \\
\hline
\end{tabular}

Abbreviations: t, time; $\mathrm{Q}$, concentration; r, correlation coefficient. in a nonuniform drug distribution. ${ }^{15,16}$ In contrast, FCVB has good transparency, induces very little refractive shifts, and permits the levofloxacin in solution to disperse evenly in the capsule and to permeate the outside uniformly. In addition, different drugs could dissolve in this uniform FCVB, and no corresponding carrier is needed.

The authors' previous studies have shown that the FCVB releases DexP in a time-dependent manner in vitro. In this study, levofloxacin released from the FCVB was stabilized at $20 \mathrm{ng} / \mathrm{mL}$ in vitro. The reason may be related to the different molecular weights and osmotic pressures of these two drugs. The molecular weight of DexP is 516.41 daltons; levofloxacin is 415.85 daltons. Solution osmotic pressures of these two drugs are also different: the solvent for DexP is saline, with an osmotic pressure of $1552.7 \mathrm{mOsm} / \mathrm{kg}$; the solvent for levofloxacin is sterile $\mathrm{H}_{2} \mathrm{O}$, and the osmotic pressure is $2 \mathrm{mOsm} / \mathrm{kg}$.

The dosage of levofloxacin released from the rabbit FCVB, at 6 hours in vitro and first day in vivo, are not as high as the $\mathrm{MIC}_{90}$ requirement for staphylococcus $(0.25 \mu \mathrm{g} / \mathrm{mL})$. The volume of the human vitreous body is about $4.0 \mathrm{~mL}$,
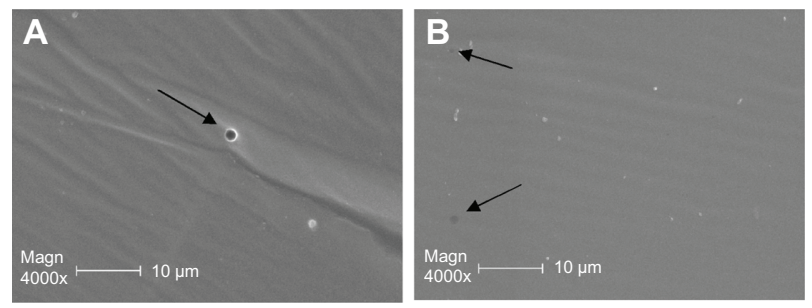

Figure 8 Scanning electron microscope images of the capsule of the foldable capsular vitreous body where (A) $300 \mathrm{~nm}-\mathrm{mm}$ apertures were observed in the capsule before release study and (B) apertures were observed at the end of release study. 
and the direct intravitreal injection of $500 \mu \mathrm{g} / \mathrm{mL} / 0.1 \mathrm{~mL}$ levofloxacin was approximately $125 \mu \mathrm{g} / \mathrm{mL}$. However, in eyes without PPV surgeries, levofloxacin is centralized and has to pass the vitreous body to the retina. In eyes after PPV, levofloxacin touches the retina directly. Other research on a rabbit FCVB demonstrated that in the $S$. aureus endophathalmitis rabbit model the FCVB with $625 \mu \mathrm{g} / \mathrm{mL}$ levofloxacin tamponade, and the culture results of the aqueous humor were sterile (Figure 9).

Recently, a clinical trial on the biocompatibility and effectiveness of a FCVB as a silicone oil substitute in human eyes has been completed at Zhongshan Ophthalmic Center. The Sun Yat-sen University Medical Ethics Committee approved the clinical trials (Zhongshan Ophthalmic Center Medical Ethics (2009) No. 07); the trials have been successfully registered with ClinicalTrials.gov (ID: NCT00910702) and in the Chinese Clinical Trial Register (ChiCTR-TNC-00000396). The results showed that the FCVB was a flexible, effective, and safe vitreous substitute over a 3 -month implantation period..$^{20}$ Thus, the FCVB may provide a combined vehicle for a vitreous substitute and an endophthalmitis DDS.

Because of the presence of the blood-ocular barrier, a plasma drug has difficulty entering the eye. In addition, eye drugs also have difficulty entering the plasma. In this study,
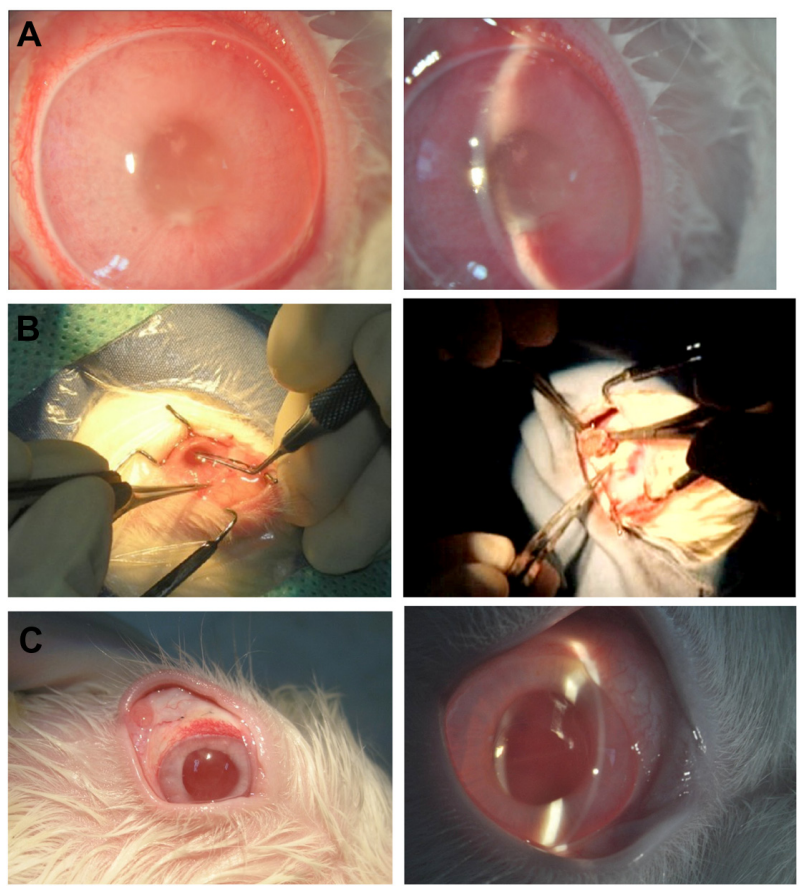

Figure 9 In the Staphylococcus aureus endophthalmitis rabbit model, the rabbit foldable capsular vitreous body (FCVB) with levofloxacin $625 \mu \mathrm{g} / \mathrm{mL}$ tamponade and the culture results of aqueous humor were sterile. (A) S. aureus endophthalmitis rabbit model, (B) surgery of FCVB tamponade, and (C) no signs of endophthalmitis were observed in the treated eye. levofloxacin release in the eye was $10-130 \mathrm{ng} / \mathrm{mL}$, so there was no measurement of levofloxacin in the plasma. ${ }^{27,28}$ Future research should focus on the effect of human FCVB combined with levofloxacin on human bacterial endophthalmitis in vitro and in vivo. Also, research studies on the investigation of other drugs are in progress, including antibiotics, antiproliferation agents, and vascular endothelial growth factor antagonists.

\section{Conclusion}

In conclusion, the rabbit FCVB released levofloxacin stably in vitro and sustainably released levofloxacin in vivo. FCVB combined with levofloxacin may provide a novel research and therapy strategy as a vitreous substitute and as a DDS for the treatment of bacterial endophthalmitis.

\section{Acknowledgments}

The authors would like to thank all the attending staff in the Zhongshan Ophthalmic Center and the Laboratory of Pharmaceutical Analysis and Quality Assessment of Sun Yat-sen University for their support. The Project of Scientific and Technique Plan of Guangdong Province supported this study (2010A090200074).

\section{Disclosure}

The authors report no conflicts of interest in this work.

\section{References}

1. Endophthalmitis Vitrectomy Study Group. Results of the Endophthalmitis Vitrectomy Study: a randomized trial of immediate vitrectomy and of intravenous antibiotics for the treatment of postoperative bacterial endophthalmitis. Arch Ophthamol. 1995;113(12):1479-1496.

2. Callegan MC, Engelbert M, Parke DW 2nd, Jett BD, Gilmore MS. Bacterial endophthalmitis: epidemiology, therapeutics, and bacteriumhost interactions. Clin Microbiol Rev. 2002;15(1):111-124.

3. Callegan MC, Gilmore MS, Gregory M, et al. Bacterial endophthalmitis: therapeutic challenges and host-pathogen interactions. Prog Retin Eye Res. 2007;26(2):189-203.

4. Jackson TL, Eykyn SJ, Graham EM, Stanford MR. Endogenous bacterial endophthalmitis: a 17-year prospective series and review of 267 reported cases. Surv Ophthalmol. 2003;48(4):403-423.

5. Han DP, Wisniewski SR, Wilson LA, et al. Spectrum and susceptibilities of microbiologic isolates in the Endophthalmitis Vitrectomy Study. Am J Ophthalmol. 1996;122(1):1-17.

6. Lifshitz T, Lapid-Gortzak R, Finkelman Y, Klemperer I. Vancomycin and ceftazidime incompatibility upon intravitreal injection. Br JOphthalmol. 2002;84(1):117-118.

7. Fiscella RG. Physical incompatibility of vancomycin and ceftazidime for intravitreal injection. Arch Ophthalmol. 1993;111(6):730.

8. Ferrer C, Rodríguez A, Abad JL, Fernandez J, Alió JL. Bactericidal effect of intravitreal levofloxacin in an experimental model of endophthalmitis. Br J Ophthalmol. 2008;92(5):678-682.

9. Ernst ME, Ernst EJ, Klepser ME. Levofloxacin and trovafloxacin: the next generation of fluoroquinolones? Am J Health Syst Pharm. 1997;54(22):2569-2584. 
10. Schwab IR, Friedlaender M, McCulley J, Lichtenstein SJ, Moran CT; Levofloxacin Bacterial Conjunctivitis Active Control Study Group. A phase III clinical trial of $0.5 \%$ levofloxacin ophthalmic solution versus $0.3 \%$ ofloxacin ophthalmic solution for the treatment of bacterial conjunctivitis. Ophthalmology. 2003;110(3):457-465.

11. Dajes JJ, Thibodeaux BA, Marquart ME, Girgis DO, Traidej M, O'Callaghan RJ. Effectiveness of ciprofloxacin, levofloxacin, or moxifloxacin for treatment of experimental Staphylococcus aureus keratitis. Antimicrob Agents Chemother. 2004;48(6):1948-1952.

12. Yildirim O, Oz O, Aslan G, Cinel L, Delialioglu N, Kanik A. The efficacy of intravitreal levofloxacin and intravitreal dexamethasone in experimental Staphylococcus epidermidis endophthalmitis. Ophthalmic Res. 2002;34(6):349-356.

13. Durand ML. Bacterial endophthalmitis. Curr Infect Dis Rep. 2009;11: 283-288.

14. Jabs DA, Newman C, De Bustros S, Polk BF. Treatment of cytomegalovirus retinitis with ganciclovir. Ophthalmology. 1987;94(7):824-830.

15. Colthurst MJ, Williams RL, Hiscott PS, Grierson I. Biomaterials used in the posterior segment of the eye. Biomaterials. 2000;21(7):649-665.

16. Yasukawa T, Ogura Y, Tabata Y, Kimura H, Wiedemann P, Honda Y. Drug delivery systems for vitreoretinal diseases. Prog Retin Eye Res. 2004;23(3):253-281.

17. Gao Q, Mou S, Ge J, et al. A new strategy to replace the natural vitreous by a novel capsular artificial vitreous body with pressure-control valve. Eye (Lond). 2008;22(3):461-468.

18. Gao Q, Chen X, Ge J, et al. Refractive shifts in four selected artificial vitreous substitutes based on Gullstrand-Emsley and Liou-Brennan schematic eyes. Invest Ophthalmol Vis Sci. 2009;50(7):3529-3534.

19. Liu Y, Jiang Z, Gao Q, et al. Technical standards of a foldable capsular vitreous body in terms of mechanical, optical, and biocompatible properties. Artif Organs. 2010;34(10):836-845.
20. Lin X, Ge J, Gao Q, et al. Evaluation of the flexibility, efficacy, and safety of a foldable capsular vitreous body in the treatment of severe retinal detachment. Invest Ophthalmol Vis Sci. 2011;52(1):374-381.

21. Liu Y, Ke Q, Chen J, et al. Sustained mechanical release of dexamethasone sodium phosphate from a foldable capsular vitreous body. Invest Ophthalmol Vis Sci. 2010;51(3):1636-1642.

22. Herbert EN, Pearce IA, McGalliard J, Wong D, Groenewald C. Vitreous penetration of levofloxacin in the uninflamed phakic human eye. $\mathrm{Br} J$ Ophthalmol. 2002;86(4):387-389.

23. Gurler B, Ozkul Y, Bitiren M, Karadede S, Gurkan T. A study on the toxicity of intravitreal levofloxacin in rabbits. Curr Eye Res. 2002;24(4):253-262.

24. Ohkubo S, Yamashita Y, Tanahashi T, Higashide T, Torisaki M, Sugiyama K. Pharmacokinetics of intravitreal injection of levofloxacin. Invest Ophthalmol Vis Sci. 2004;45:E-abstract 3951.

25. Haller JA, Bandello F, Belfort R Jr, et al; OZURDEX GENEVA Study Group. Randomized, sham-controlled trial of dexamethasone intravitreal implant in patients with macular edema due to retinal vein occlusion. Ophthalmology. 2010;117(6):1134-1146.

26. Pavesio C, Zierhut M, Bairi K, Comstock TL, Usner DW; Fluocinolone Acetonide Study Group. Evaluation of an intravitreal fluocinolone acetonide implant versus standard systemic therapy in noninfectious posterior uveitis. Ophthalmology. 2010;117(3):567-575.

27. Mounier M, Ploy MC, Chauvin M, Adenis JP, Denis F. Study of intraocular diffusion of ofloxacin in humans and rabbits. Pathol Biol (Paris). 1992;40(5):529-533. French.

28. Sugioka K, Fukuda M, Komoto S, Itahashi M, Yamada M, Shimomura Y. Intraocular penetration of sequentially instilled topical moxifloxacin, gatifloxacin, and levofloxacin. Clin Ophthalmol. 2009;3:553-557.
International Journal of Nanomedicine

\section{Publish your work in this journal}

The International Journal of Nanomedicine is an international, peerreviewed journal focusing on the application of nanotechnology in diagnostics, therapeutics, and drug delivery systems throughout the biomedical field. This journal is indexed on PubMed Central, MedLine, CAS, SciSearch $\AA$, Current Contents ${ }^{\circledR} /$ Clinical Medicine,

\section{Dovepress}

Journal Citation Reports/Science Edition, EMBase, Scopus and the Elsevier Bibliographic databases. The manuscript management system is completely online and includes a very quick and fair peer-review system, which is all easy to use. Visit http://www.dovepress.com/ testimonials.php to read real quotes from published authors. 